\title{
AS EMPRESAS FAMILIARES NO BRASIL
}

\author{
J. Sérgio R. C. Gonçalves
}

A partir do momento em que Schumpeter, reconhecendo que o progresso econômico se transformava em atividade de grupos de especialistas e admitindo também que o próprio progresso técnico passava a ser cada vez mais um processo coletivo e, portanto, despersonalizado, estavam, desde então, criadas as bases para a elaboração do que pode ser identificado como "teoria clássica das organizações empresariais". Isso terá também estimulado Peter Drucker a propor a substituição do magnata pelos técnicos e administradores profissionais como comandantes da empresa privada. A partir desse momento, porque, conseqüência da teoria que se elaborou, a empresa familiar recebeu um estigma que iria marcá-la pelas décadas seguintes: o estigma da incompetência pressuposta.

Schumpeter imaginou a unidade industrial gigantesca, perfeitamente burocratizada, não deixando espaço para as pequenas e médias empresas, expropriando os seus proprietários e caminhando para reduzir o empresário à condição de assalariado. Peter Drucker, na me- dida em que a burocracia competente se identifica com a organização moderna, segue nessa mesma linha, percebendo nos executivos profissionais, que nascem com essa mesma organização, os novos líderes, exercendo uma liderança que se baseia na competência; eles são os especialistas e os administradores profissionais.

A essa competência opõe-se, inevitavelmente, a incompetência dos empresários e suas empresas familiares, identificável especialmente nos pontos seguintes:

a) a empresa familiar permite-se uma organização informal, confusa e incompleta;

b) ela adota como valor básico a confiança pessoal, em prejuízo da competência, tornando-se incapaz de contar com técnicos e especialistas de gabarito;

c) ela pratica o nepotismo sob diversas formas, impossibilitando definitivamente a profissionalização;

d) finalmente, a empresa familiar é imediatista, o que impede qualquer forma de planejamento empresarial.
Como resultado dessa avaliação, a empresa familiar passou a ser pensada, quando o foi, em função daquele que seria o seu momento trágico, ou seja, o momento da sucessão. Imaginado com o mesmo fatalismo que marca o teatro clássico grego. Nesse caso, o inevitável podia até mesmo ser comprovado estatisticamente: em todo o mundo, a menor parte das empresas familiares sobrevive numa segunda geração e uma minoria desprezível suporta a terceira.

Até a década de 50, a empresa familiar brasileira teve presença quase absoluta em praticamente todos os segmentos da economia nacional, desde a atividade agrícola até o sistema financeiro, passando pela indústria têxtil, de alimentação, de serviços e de meios de comunicação. A partir daí, iniciado o grande projeto de desenvolvimento e modernização nacional, ela passaria a partilhar cada vez mais espaços com as empresas multinacionais e com as estatais.

Não se deve avançar no tema, entretanto, sem o cuidado de deixar claro o que se entende por empresa familiar, visto que, na maioria das ocasiões, pressupõe-se o que ela 
seja, o que pode não ser exatamente verdadeiro. Muitas vezes, pretendese que ela seja aquela na qual convivem duas ou mais gerações de uma mesma família, o que, na verdade, não é necessário que ocorra. Em outras, não menos freqüentes, fazse a distinção entre a empresa familiar e a empresa individual, quando não se leva em conta que todo indivíduo participa pelo menos de uma família de formação, aquela em que nasceu e foi educado, sendo muito comum que tenha ainda uma família de procriação, a que ele mesmo formou pelo casamento.

$\mathrm{O}$ que de fato caracteriza a empresa familiar é a coexistência de três situações, que são:

a) a empresa é propriedade de uma família, detentora da totalidade ou da maioria das ações ou cotas, de forma a ter o seu controle econômico;

b) a família tem a gestão da empresa, cabendo a ela a definição dos objetivos, das diretrizes e das grandes políticas;

c) finalmente, a família é responsável pela administração do empreendimento, com a participação de um ou mais membros no nível executivo mais alto.

A Metal Leve tem sido um exemplo perfeito de dois ou mais empresários de diferentes famílias participando do mesmo empreendimento, sendo mais correto qualificá-la como empresa multifamiliar, muito próxima da empresa familiar, mas com características e principalmente problemas muito específicos.

De qualquer forma, é essa coexistência de situações que vai permitir que a cultura familiar penetre na esfera da empresa, marcando-a em diferentes graus com os seus valores, que, por sua vez, determinam comportamentos específicos. Por isso mesmo é que faz sentido estudar-se a empresa familiar brasileira tendo sempre como ponto de partida o estudo da cultura da família empresária no Brasil.

Essa família tem sido historicamente orientada por dois referenciais básicos: o patrimonialismo e o patronato político.

O patrimonialismo sustentou-se nas famílias patriarcais, formando, com muita freqüência, parentelas, sob a chefia de um senhor. Em termos práticos, é uma visão patrimonialista que permite à família administrar o patrimônio pessoal e o da empresa como se fosse único e privado. Ainda nos dias atuais, são muitas as famílias que consideram os ativos da empresa, inclusive os que compõem o ativo fixo, como propriedade pessoal, enquanto os passivos são entendidos como obrigações da empresa. É o que justifica o antigo ditado popular que se refere ao "dinheiro em dois bolsos, mas de um dono só".

As famílias, herdando valores próprios de uma estrutura patriarcal e adotando um comportamento patrimonialista, tendem a adotar, quase que necessariamente, nas suas empresas, um comportamento paternalista. Não existe, então, uma relação profissional e jurídica entre a empresa e o empregado, mas uma relação pessoal, necessariamente orientada e disciplinada pelo patrão e dono, baseada em fidelidade e mútua confiança, o que acontece principalmente durante a gestão e administração do fundador. Não pode ser esquecido, porém, que muitas empresas familiares, ou por maturidade, ou mesmo por terem de enfrentar no mercado de trabalho a concorrência de grandes empresas multinacionais, foram libertadas das práticas paternalistas. Um recurso usado com bons resultados para chegar-se a isso tem sido a criação de fundações, que, comumente, assumem atividades assistenciais, de treinamento, culturais e de lazer; essas fundações têm condições de realizar de maneira mais madura e aperfeiçoada uma intermediação entre a empresa, o empregado e a família, na qual o fundador ou seus sucessores estarão simbolizados na instituição, que os dispensa de uma presença física e direta nesse relacionamento.

De qualquer forma, é a visão patrimonialista que provoca as grandes inconsistências da empresa familiar: o autoritarismo, o nepotismo, o uso da confiança pessoal, e não da competência, para a escolha de colaboradores, implicando ainda o paternalismo como forma de relacionamento com os empregados. Com certeza, em grau extremo, o patrimonialismo leva a um fracasso inevitável da empresa. Mas não é assim que ele se manifesta, quase sempre sendo atenuado e disciplinado por diversos condicionantes, sob a forma de valores sociais. Mesmo assim, é um patrimonialismo sobrevivente que torna a empresa familiar particularmente vulnerável em determinados momentos, aqueles que representam grandes transições e que podem ser chamados de ritos de passagem, que marcam etapas na vida da empresa.

Nos empreendimentos bemsucedidos, há um momento em que o fundador tem necessidade de rever suas atitudes e seus procedimentos. A relação entre criador e criatura deve ser alterada, porque a criatura, a empresa, passa a ter necessidade de determinadas competências que ele, o criador, não possui, mas que deverá ser capaz de identificar, localizar e alocar. Deve ser lembrado que, ainda na década de 50, o desafio envolvido nessa transição, pela inexistência de executivos em número suficiente e com formação adequada, era muito grande, o que levou muitas vezes o empresário a cometer equívocos capazes de provocar o fracasso da empresa. Já há algum tempo, porém, boas escolas de administração, consultores competentes, disponibilidade de litera- 
tura e de informações asseguram à empresa familiar a possibilidade de formar uma competência intelectual adequada às suas necessidades. Com certeza, porém, não poderá haver espaço para qualquer prática de nepotismo nem mesmo para a manutenção de formas de relações pessoais baseadas em simpatias e sentimentos de confiança.

Também no mais comum das vezes, as empresas familiares devem realizar um ou mais "saltos", que tomam a forma de projetos, envolvendo investimentos expressivos. Trata-se de um outro momento de transição, quando uma possível persistência de conceitos e procedimentos vindos do antigo patrimonialismo pode tornar a empresa extremamente frágil. É ele, em última instância, que permite que os estudos de mercado e os projetos técnicos sejam substituídos pela intuição e pela improvisação, quase sempre com resultados desastrosos, uma vez que terão sido captados recursos e assumidos índices altos de endividamento, sem que se obtenha o retorno apenas imaginado. Os riscos são ainda maiores quando um projeto passa a ter apenas um pretenso objetivo de investimento, mas, de fato, é montado diante da possibilidade de obter recursos a custos subsidiados em um Banco de Desenvolvimento, que podem ser desviados para complementação de um capital de giro já insuficiente ou mesmo para fins totalmente diferentes e até alheios à empresa.

É sabido que a empresa familiar no Brasil enfrenta tipicamente problemas em sua capitalização adequada e em sua capacidade de sustentar um projeto mais pesado de investimento. Durante muito tempo, a possibilidade prática e viável para a captação de recursos para investimentos foi representada pelo Banco Nacional de Desenvolvimento Econômico e Social (BNDES). É realmente expressivo o número de em- presas familiares que puderam realizar competentemente a sua vocação contando com o apoio dessa instituição. Mas essa afirmação não invalida a observação de que, com grande freqüência, o relacionamento entre os empreendedores famili- os nasce da necessidade de capitalização do empreendimento, em tese, a alternativa de abertura do capital com oferta pública de ações seria a mais aceitável para o empresário familiar. No entanto, quando ela chegou a ser experimentada, acabava

\section{É a visão patrimonialista que provoca as grandes inconsistências da empresa familiar: o autoritarismo, o nepotismo, o uso da confiança pessoal, e não da competência, para a escolha de colaboradores.}

ares e os técnicos do BNDES foi duro e difícil. Ainda uma vez, a cultura patrimonialista impedia o reconhecimento de que um Banco de Desenvolvimento atua a partir de políticas definidas em nível macroeconômico, pretendendo atingi-las interagindo com a iniciativa privada. Era mais fácil que o empresário pensasse que obteve um empréstimo lastreado em garantias pessoais suas, para ser usado na sua empresa onde e como quisesse.

Caso o BNDES conserve em seus arquivos os projetos apresentados por empresas familiares que foram aprovados depois de feitas as devidas análises, sendo entendidos como compatíveis com os objetivos de um plano de desenvolvimento da economia nacional, mas que acabaram sendo mal-sucedidos, levando essas empresas à falência, existirá, então, uma documentação especialmente rica que futuramente deverá ser estudada por quem tenha interesse na história das empresas industriais familiares no Brasil.

Uma possibilidade, que muitas vezes se apresentava como interessante, mas que, nos tempos mais recentes, se torna praticamente imperativa, é aquela que leva ao processo de busca de novos sócios ou parceiros. Enquanto essa procura de sóci- esvaziada na maioria dos casos, porque os direitos de acionistas minoritários sempre foram limitados e assim mesmo pouco respeitados, o que permitia transformar-se o processo em não mais do que um expediente para a captação de recursos a custos muito baixos, sem a contrapartida de responsabilidades maiores. Além disso, não será demais lembrar que o mercado de ações no Brasil foi sempre pouco expressivo nos volumes que movimenta, tendo-se tornado, no decorrer do tempo, cada vez mais seletivo em função de interesses especulativos imediatistas.

Por outro lado, foi sendo ampliada a possibilidade de contar com sócios institucionais, isto é, bancos, especialmente bancos de negócios, fundos de previdência privada e seguradoras. Mas o que se pode concluir, com base em observação de comportamentos praticados até agora, é que, na grande maioria dos casos, esses sócios surgem em momentos de crise financeira profunda na empresa familiar, trazendo o apoio representado por novos recursos e providenciando-se o saneamento do empreendimento para que se torne viável a sua venda subseqüente. Assim, e com mais rigor, não há propriamente a formação de uma parceria, mas a adoção de uma solução, 
a menos inconveniente, para um problema que envolve credores e devedores, minimizando-se prejuízos de parte a parte.

Com o rápido processo que passou a ter o nome de "globalização", as empresas nacionais, inclusive as familiares, têm reconhecido a necessidade imperativa, como condição básica para a sobrevivência, de buscar e conseguir sócios estratégicos. quando já se deixou de lado o método tradicional, do patrimônio líquido ajustado, adotando-se sistemas mais sofisticados, como o do "fluxo de caixa descontado" ou o do "múltiplo do lucro sustentável", ainda continuam a existir aspectos totalmente subjetivos, o que se torna mais sério quando se coloca em discussão o valor de um eventual fundo de comércio (goodwill). É bas-

\section{Boas escolas de administração, consultores} competentes, disponibilidade de literatura $e$ de informações asseguram à empresa familiar a possibilidade de formar uma competência intelectual adequada às suas necessidades.

Nesse novo cenário, importam de fato: $\mathrm{o}$ acesso à tecnologia, o monopólio cada vez maior das grandes corporações multinacionais, a possibilidade de assegurar a participação no mercado, seja qual for ele, uma vez que eles passam a ser controlados pelas mesmas multinacionais, que formam cadeias integradas do suprimento às vendas, numa situação inédita, que tem exemplo acabado na indústria automobilística. Portanto, o parceiro estratégico será sempre um sócio estrangeiro.

As famílias que se tenham conservado fiéis à ética patrimonialista, mesmo que busquem, não encontrarão esse tipo de parceiro, passando a viver a experiência de uma morte anunciada. Mas é preciso reconhecer que mesmo os empresários que souberam livrar-se da cultura transmitida pelos mais velhos ainda assim enfrentam e enfrentarão dificuldades.

A formação de uma joint venture, quando se entende por ela a formação de uma associação, começa por uma negociação sempre difícil em torno do valor do negócio. Mesmo tante fácil entender que, para a família empresária, especialmente para o seu fundador, a sua empresa terá sempre um valor muito específico, algo que a distingue de qualquer outra: afinal, com muita freqüência, o próprio nome da empresa é dado a ela pela família, e o prestígio econômico e social da família é dado a ela pela empresa. Com certeza, porém, negociadores e executivos profissionais, representando os interesses de uma empresa multinacional, não serão comovidos pelos sentimentos da família que se senta ao outro extremo da mesa para negociar, nem sempre tendo o bom senso de fazer-se representar também por negociadores profissionais.

Vencida a primeira etapa, definindo-se um valor para o negócio, segue-se um momento constrangedor: os números só serão definitivos depois de feito um trabalho muito cuidadoso de auditoria (dull dilligence). Para a empresa familiar, será uma experiência sempre dolorida, implicando a intromissão de homens desconhecidos naquilo que foi sempre identificado como privativo familiar, algo como entregar a um policial os velhos álbuns de fotografias da família para que ele identifique pais e avós, revolvendo-se ossadas e histórias nem sempre edificantes.

Finalmente, mas não o mais fácil para a família proprietária, serão redigidos os documentos que darão forma jurídica à associação, quando se definem pontos extremamente estratégicos, tais como: decisões que exigirão quorum qualificado; política de distribuição de lucros; composição dos órgãos de direção; e estabelecimento do "direito de preferência" e do "direito de saída". Todos eles, e ainda mais outros que poderiam ser lembrados, implicam penosas renúncias a serem feitas pela família, que teria tido sempre o poder absoluto.

Com certeza, em quase todas as situações concretas, a associação envolve uma grande negociação, que é feita entre partes com poderes econômicos significativamente diferentes. Por isso mesmo, o que tem ocorrido durante a última década, desde que se iniciou a "globalização", vem sendo muito menos um processo de associações estratégicas e muito mais o de compra da empresa familiar nacional pela multinacional feita num único momento ou então num processo que comporta diversas etapas.

Finalmente, e ainda quando se pensa sobre os momentos de transição que são experimentados pela empresa familiar, resta lembrar aquele que é exatamente o mais enfatizado e estudado: a passagem do comando da empresa, especialmente quando ela envolve o seu fundador. Com relação a essa passagem, devem ser propostas pelo menos três considerações.

Em primeiro lugar, é inevitável que, na empresa familiar brasileira, o processo sucessório seja, ainda que em graus diferentes, orientado por uma cultura que a configurou 
como patriarcal e patronal, o que leva ao privilégio do filho homem primogênito como sendo o sucessor necessário. Além deste, existirão ainda outros comportamentos, pressupostos como os melhores, que devem orientar as sucessões, numa segunda, terceira ou em outras gerações. O que não pode ser esquecido, porém, é que a família, como instituição, experimentou mudanças profundas, que devem ser compreendidas em função de uma "revolução das individualidades" ocorrida durante a segunda metade deste século e que está dando a cada membro da família uma liberdade, em relação a ela mesma, que é inédita no mundo moderno ocidental. Com isso, tanto o casamento deixa de ser uma instituição perene, como as relações entre pais e filhos transformam-se, deixando de existir a velha patria potestas e o antigo temor reverencial. E é assim que a empresa familiar, no Brasil, da mesma forma que no resto do mundo, tem a enfrentar o desafio de ajustar-se a uma nova família, organizada democraticamente, justificável enquanto os seus membros entendam que ela lhes dá satisfação.

Em segundo lugar, deve ser lembrado que a família é um pequeno grupo social, no qual são desenvolvidos os sentimentos mais fortes que possam marcar um ser humano: amores e ódios; as empatias e as repugnâncias criadas em aparente subjetividade; a proximidade e a rejeição; a proteção castradora e a indiferença; e, muito especialmente, a inveja. Esse mundo familiar, povoado por forças ocultas e alguns fantasmas, pode ser transferido para o mundo da empresa, quando inevitavelmente os resultados serão lamentáveis. Do encontro entre as duas esferas, a do privado (a família) e a do público (a empresa), surgem algumas relações que são particularmente perigosas: entre irmãos e/ou primos, no momento da sucessão; entre sogro e genro; entre avô e neto; mas nenhuma mais perigosa do que a relação entre a sogra e a nora, mulher do filho sucessor. Os jogos do inconsciente da família poderão não prejudicar a sua empresa enquanto ela estiver sob o comando de um patriarca, que usa do com muitas viagens e dominará alguns idiomas. Se não bastasse, poderá ser um excelente atleta, praticando modalidades esportivas preferencialmente exóticas. Enfim, o filho sucessor é formado de maneira a ser sadio, simpático, bem in-

\section{É sabido que a empresa familiar no Brasil enfrenta tipicamente problemas em sua capitalização adequada e em sua capacidade de sustentar um projeto mais pesado de investimento.}

seu poder absoluto não para solucionar os conflitos, mas para disciplinálos. Ou enquanto eles puderem de fato ser solucionados ou ao menos orientados pelos membros da família, com ou sem o apoio de especialistas no assunto. Deve-se admitir, porém, que esse problema diz respeito a toda empresa familiar, e não apenas às brasileiras.

Em terceiro lugar, não há como admitir que, na grande maioria dos casos, os empresários conseguem ser, de forma aparentemente incoerente, competentemente equivocados na formação dos filhos sucessores. Aqui, sem dúvida, o caso brasileiro, é exemplar. Numa sociedade marcada pelas mais profundas desigualdades sociais imagináveis e até inimagináveis, esse filho tem sido educado para exercer o poder sem limites. Desde a infância, ele é educado nas melhores escolas, que se destinam aos filhos das elites, num processo que tem continuidade na universidade. Ao mesmo tempo, ele freqüenta os clubes de elite e desenvolve uma rede de relações pessoais úteis. Uma vez terminado o curso universitário, ele poderá obter o seu grau de mestrado ou doutorado numa das instituições de ensino de maior renome internacional. Conhecerá o mundo formado, bem relacionado e autoconfiante. Ao assumir uma posição de comando na empresa da família, ele penetra em um mundo povoado por seres que ele jamais conheceu e enfrenta problemas que não podem ter a solução que mais lhe convém, apenas por um ato de vontade sua. Com certeza, esse não é o maior problema que desafia a empresa familiar brasileira, mas, nos tempos mais recentes, tem sido a causa mais freqüente dos seus fracassos. De qualquer forma, poderá com algum otimismo ser entendido como resultado de um modismo, passageiro como todos...

Identificou-se, inicialmente, como segundo traço marcante na empresa familiar brasileira, o patronato político. Com efeito, praticado durante todo o Império, quando se formou a elite dos "barões do café", prosseguiu durante a Primeira República, sustentado pelo primeiro Convênio de Taubaté, de 1905, tendo passado pela Segunda República, pelo Estado Novo, conseguindo estar sempre vivo. Quando o "nacionalismo desenvolvimentista", a partir dos anos 50, foi adotado como política do Estado Nacional, o patronato político soube aproveitar-se dos financiamentos subsidiados e disponíveis nos Bancos de Desenvolvi- 
mento, das tarifas protecionistas, que criavam reservas de mercado, tanto quanto dos incentivos fiscais, que pretenderam, em tese, contemplar áreas especialmente empobrecidas, como o Nordeste e o Norte, ou atividades estratégicas, como a pesca ou o turismo. O patronato político sobreviveu até mesmo durante o longo período autoritário, não sendo descabido entender que realmente o autoritarismo foi imposto para que ele continuasse a ser praticado.

A prática do patronato, assegurada pelo Estado protetor e mantida por tanto tempo, provocou, além do estímulo à incompetência, uma outra grande distorção. O empresário, acostumado-se a ter o Estado a servi-lo, nunca entendeu que seria necessário e legítimo assumir encargos impostos por ele, o Estado servidor, tanto os impostos, especialmente o tributo sobre rendimentos, como as obrigações trabalhistas ou ainda o respeito ao meio ambiente. Por esse motivo, as empresas familiares no Brasil sempre se sentiram tranqüilas e mesmo justificáveis quando adotavam procedimentos que são eufemisticamente rotulados com o nome de "informalismo".

O neoliberalismo e a "globalização" fizeram com que esse quadro fosse completamente modificado, o que aconteceu desde os primeiros anos da década de 90 . Sem que tivesse havido um período de transição, a empresa nacional, e especialmente a familiar, foi obrigada a ser imediatamente eficiente, criando condições para sobreviver num mundo de competição terrível. Até o presente, com certeza, os resultados foram totalmente negativos. Setores inteiros, que historicamente foram espaços ocupados por empresas familiares, foram rapidamente assumidos e controlados por grandes empresas multinacionais, o que aconteceu, como um dos maiores exemplos disso, com a chamada indústria de autopeças.
Uma análise dos pontos fracos da empresa familiar no Brasil, arrematada com a observação de que ela vive um momento extremamente difícil, não pretende de nenhuma maneira sugerir a sua inviabilidade nos tempos atuais. Nem pretende que o único caminho possível seja aquele que tem sido apontado com mais freqüência, quando a família estaria deixando de ser empresária para tornarse acionista. Essa proposta seria arriscada, se não fosse antes inútil, na medida em que simplesmente nunca haverá nenhuma força capaz de impedir a força empreendedora dos indivíduos que se tornam empresários e querem ter a sua empresa.

É verdade que a empresa familiar, não só no Brasil, sempre enfrentou desafios que levam constantemente a grandes distorções. Mas é verdade também que existem atualmente recursos, proporcionados por estudos e pesquisas, que permitem vencer esses desafios. Por outro lado, mas obrigando ao aperfeiçoamento, a inviabilidade histórica de conservação do patronato político, desaguando na criação de uma situação de concorrência implacável, transforma a competência em condição de sobrevivência para a empresa familiar.

Por outro lado, a família nuclear, que desde o século passado é aquela que se encontra nas origens da empresa familiar, passa por transformações imensas. Não será descabido acreditar que uma configuração familiar, menos castradora que aquela que sobreviveu por pelo menos um século e meio, poderá abrir espaços para relações familiares mais equilibradas, reduzindo-se os riscos de as forças inconscientes, que movem as pessoas no âmbito do privado, penetrarem na esfera da empresa. Mais ainda, e na medida em que uma nova família pretende estar orientada pelo respeito às individualidades de seus membros, alguns conceitos e normas, como o de propriedade familiar e herança, deverão ser revistos. O individualismo que se pleiteia agora, mantendo-se uma postura de coerência, aponta para a herança e sucessão definidas por ato de vontade individual, isto é, o testamento, deixando de ter sentido a figura do herdeiro necessário e todo o conjunto de regras legais que tornam obrigatórios determinados procedimentos.

Também é particularmente animador para a empresa familiar que, com toda certeza, as previsões de Schumpeter e de Peter Drucker não se confirmaram. A grande corporação, organizada cientificamente, passando a ser identificada como "mecanicista", teve as virtudes do passado transformadas em vícios: a departamentalização rígida, a especialização, a burocratização, o planejamento rígido, tudo isso impede a criatividade, a flexibilidade e a capacidade de adaptação a transformações. Necessariamente, no outro extremo, muitos dos antigos vícios e das aparentes incoerências da empresa familiar, desde que canalizados competentemente, transformamse em virtudes, as mais desejadas no momento atual.

Por último, mas não menos importante, é possível pensar que o empresário e a sua empresa familiar virão a ser a sustentação de um liberalismo capitalista amadurecido, em oposição ao neoliberalismo do fim do século, que empobrece absurdamente o modelo capitalista quando passa a reconhecer no lucro o seu único objetivo, a ser alcançado mesmo que ao preço do aviltamento da dignidade humana.

J. Sérgio R. C. Gonçalves é Advogado, Filósofo, Diretor Administrativo de empresa no setor de autopeças e Consultor.

E-mail: mandelli@federalnet.com.br 